\title{
TOURISTS’ ACCOUNTS OF RESPONSIBLE TOURISM
}

\begin{abstract}
'Responsible tourism' has become an established area of tourism research and practice and is typically understood as a broad set of tourist interactions that engage with and benefit local communities and minimize negative social and environmental impacts. Extant research however has adopted a largely top down approach to understanding responsible tourism that has marginalized the voices of tourists. This study investigates tourists' own accounts of responsible tourism experiences, finding that these intersect with but also deviate substantially away from established conceptions of the phenomenon. We show that tourists' accounts can be delineated according to the extent to which they display inner- versus outerdirected goals, and the degree of involvement in responsible tourism as a cultural identity.
\end{abstract}

Keywords: Consumer narratives, responsible tourism, tourist identities.

\section{INTRODUCTION}

'Responsible tourism' has become an established area of tourism research and practice. Although it shares much in common with 'sustainable tourism', 'eco-tourism', 'ethical tourism' and other related forms of socially conscious tourism practice, the label of 'responsible tourism' is by far the most favoured industry term. Evidence suggests that tour operators are almost five times as likely to use 'responsible tourism' as any alternative label (SNV 2009). This is reflected in the provision of tourism products specifically branded as 'responsible' experiences and targeted at a distinct market niche seeking to engage in more responsible forms of tourism (Goodwin \& Francis 2003).

Recent economic conditions may have stalled the previously rapid growth of this niche, but it retains a significant, albeit small, share of the overall tourism market. It currently accounts for more than $\$ 180 \mathrm{~m}$ of business in the UK (Co-operative Group 2012) and internationally appears to have weathered the economic downturn relatively better than many other forms of tourism, meaning that it is still 'a relatively good time to be providing a responsible holiday'(SNV 2009: 21).

The meaning of responsible tourism, both in theory and practice, has been the subject of considerable debate. Amongst practitioners, there are several industry protocols on responsible tourism, which look to define its key principles and practices. For instance, the 2002 Cape Town Declaration characterizes responsible tourism in terms of: (i) minimizing impacts; (ii) generating economic benefits for host communities; (iii) involving local people in decision making; (iv) conserving natural and cultural heritage; (v) providing meaningful connections between tourists and local people; and (vi) being accessible and culturally sensitive (World Tourism Market Responsible Tourism 2013). As Caruana and Crane (2008) have shown, such constructions of responsible tourism by industry actors also help define the meaning and possibilities for responsible tourism among consumers. That is, consumers of responsible tourism do not exist as a pre-defined category waiting to be discovered, but that conceptions of responsible tourism articulated by the industry are the contours around which market segments are drawn.

Whilst we might expect marketers to reinforce a particular perspective in order to segment 
their customers and make responsible tourism products readily identifiable and easy to communicate to the market, we should not assume that consumers necessarily integrate these typified constructions of responsibility so passively, nor uniformly. Indeed, consumers are readily able to interpret, transform and contest the meanings of the products, services and brands they experience (Holt 2002). To date, however, whilst there is a great deal of research emerging in the field of responsible tourism, the majority is focused on either business perspectives such as marketing and CSR initiatives (Manente, Minghetti, \& Mingotto 2012), or the extent to which businesses live up to their promises (Frey \& George 2010), or on locals or host perspectives (e.g. Sin 2010). By contrast, there are relatively few studies of tourists' own perspectives on responsibilities (Mahrouse 2011). For instance, whilst Stanford (2008: 258) highlights the importance of placing 'the visitor at the center of the responsible tourism debate by exploring what it means to be a responsible tourist' she still takes an industry perspective to interview supply side perspectives on the value of responsible tourists' actions.

As a consequence, there is a real dearth of knowledge of tourists' own understandings of responsible tourism or indeed of how tourists construct their own activities as 'responsible'. We suggest that without this knowledge, we may be laboring under a fundamental misunderstanding of the consumer's beliefs about what it means to be responsible, how they reconcile their touristic actions as responsible or irresponsible, and the extent that there is homogeneity in how responsible tourism is interpreted by the tourism market.

This study therefore seeks to examine tourists' own accounts of responsible tourism, with a view to developing a more bottom-up conceptualization of the phenomenon. Our evidence suggests that although some tourist's accounts do adhere to a standard interpretation of responsible tourism as promulgated by the industry, the concept of responsible tourism is actually far from coherent, stable or uncontested. Consumers construct their experiences of responsible tourism in a variety of unexpected ways that, at times, deviate from the conventional view to such an extent as to appear almost contradictory. Thus, rather than confirm the existence of a single 'tribe' of responsible tourists united by a coherent, shared cultural ethos, the findings suggest significant heterogeneity in consumer conceptions of responsible tourism. Our analysis both describes this heterogeneity, and seeks to account for it in terms of the underlying drivers and identifications of tourists.

\section{RESPONSIBLE TOURISM AND RESPONSIBLE CONSUMERS}

The concept of 'responsible tourism' has been extensively researched over a long period. More than twenty five years ago, Krippendorf recognized that tourists were becoming more complex in their needs, and that the industry would have to adopt more 'environmentallyorientated and socially responsible' (1987: 174) marketing practices in order to maintain satisfaction levels into the future for a more demanding and segmented market. Such attention to responsible tourism is part of a broader trend towards considering the social and environmental impacts of business activity, typically captured under the label of corporate social responsibility (CSR). Whilst its theoretical orientations are quite diverse (Garriga \& Melé 2004), a core contribution of CSR research has been to shift towards a stakeholder model of the firm which views business as, 'an open and flexible system made up of diverse actors active in a network of relationships with various other actors,' (Maignan \& Ferrell 2004: 5).

In practice, CSR has often become operationalized in terms of what managers inside the corporation think that external stakeholders, especially consumers, expect of them. Thus, 
'marketplace polls suggest that a positive relationship exists between a company's CSR actions and consumers' reactions to that company and its product(s)' (Bhattacharya \& Sen 2004: 9). This conception of CSR as an attempt to appeal to meet the interests of stakeholders has similarly driven much research and practice in responsible tourism. Wheeller (1990), for instance, identified that the concept of responsible tourism emerged in response to concerns regarding the impacts of mass tourism development, and to distinguish 'alternative' forms of tourism. This is not to say that the idea of responsible tourism, like sustainable tourism, is without its critics with some seeing it merely as a self-justification for the continued growth of tourism markets (Wheeller 1993). Notwithstanding such critiques, the adoption of responsible tourism as an umbrella term for a wide range of social responsibility practices by industry actors and tourists themselves is by now fairly well established.

This has given rise to a burgeoning stream of literature which is developing in a number of different ways. In outlining the different research agendas in responsible tourism, Bramwell, Lane, McCabe, Mosedale and Scarles identify five main areas: the production-consumption nexus; types of actor relations; the role of different actors in owning issues of responsibility (and their involvement in an attitudes towards responsibility) and finally; the political assumptions underpinning responsible tourism (2008). This means that studies have varied in terms of how they frame the loci of responsible tourism. Acknowledging that a potentially wide number of stakeholders might play a role, most studies have tended to focus on either host communities, tourism producers - and how they influence responsible tourism - or consumers of responsible tourism themselves.

For example, a variety of studies have explored the ways in which marketing constructs responsibility issues (e.g. Caruana \& Crane 2008, 2011; Frey \& George 2010). Shepard (2003) shows how representations of 'tread-lightly' ecotourism can exploit and exclude others. Other studies have framed responsibility around individual consumer behaviors, such that salient consumer attitudes (e.g. pro-environmental concern) shape the preferences of 'eco tourists' (Krider, Arguello, Campbell and Mora 2010). Much of this new research is emerging on the application of responsible tourism in practice, but despite Bramwell et al.'s (2008) identification of the importance of understanding different actor perspectives, most research to date has been focused on the perspectives of businesses and host communities, with relatively little attention thus far to consumers' experience and understanding of responsible tourism. This is a reasonable approach since tourists are perhaps not expected to be as aware of the consequences of their actions as in other consumer contexts (Krippendorf 1987).

Subsequent studies that identified consumer demand for more responsible tourism (e.g. Goodwin \& Francis, 2003) led to the assumption that groups of responsible tourists were out there waiting to be discovered by tourism operators. Responsible tourism (or 'sustainable', 'eco' or 'ethical' tourism) thus became established as a viable market segment with a distinctive set of attitudes and behavioral dispositions (e.g. Dolnicar \& Leisch 2008). Clearly, tourist motivations combine dispositional and situational factors (Fodness 1994; Gnoth 1997; McCabe 2000), tourism decisions and outcomes are determined by emotional factors related to both push motivations and pull factors of the destination (Goossens, 2000). Sirgy argues for the need to link goal theory to drivers for, and outcomes of, tourist experiences that lead to improved subjective wellbeing (2010). However, there is a lack of knowledge linking motivational goals and outcomes to consumer experiences in the context of responsible tourism. 
In CSR consumer research, responsible consumers have also been aggregated on the basis of common demographics where income, gender, marital status, education and occupation are potential indicators of willingness to pay for responsible products (Roberts 1995).

Responsible consumers have been identified as sharing higher levels of concern for a range of social, environmental and ethical issues, leading to terms such as ecologically and/or socially 'conscious' consumers (Minton \& Rose 1997; Webster 1975). A final strand of research has attempted to further group consumers around beliefs, motivations and values (Hendarwan 2002). Much of the work in this area takes its lead from consumer behavioral modeling theory (Ajzen \& Fishbein 1980), which assumes that common traits (e.g. moral obligation, self-identity and social concern) enable favorable product attitudes, accounting for higher levels of purchase activity amongst this segment (Shaw, Shiu \& Clarke 2000).

Despite these advances in profiling responsible consumers, it has become increasingly apparent that 'behavioral patterns are not univocally consistent with attitudes' (Vermeir \& Verbeke 2006: 169) and various authors now question the link between attitudes and purchase behaviors in the CSR marketplace (e.g. Bray, Johns \& Kilburn 2010). According to Valor, a lack of capacity to assimilate complex information makes it difficult for consumers to 'choose responsibly all kinds of products, from salt to travel agencies' (2008: 322). Rather than demonstrating consistent behaviors, consumers are unpredictable and unmanageable (Gabriel \& Lang 1995). Consumers may well express a desire to be responsible when questioned in surveys but when it comes to acting upon this in the marketplace these motivations are readily traded off with other attributes such as price, quality and convenience (Devinney, Auger \& Eckhardt, 2010).

This has problematized the idea of a coherent segment or tribe of responsible consumers in the marketplace, such that 'the notion of ethical consumerism is too broad in its definition, too loose in its operationalization, and too moralistic in its stance to be anything other than a myth' (Devinney et al. 2010: 9). That is, much of the work in this area has idealized the noble intentions and behaviors of 'ethical' consumers with little basis in reality. Consumer behaviors with respect to responsibility, Devinney et al. (2010) suggest, are much more inconsistent, contingent and self-interested than the myth would suggest.

This connects with a broader literature in consumer research about the cultural role of market segments in consumer experiences of "brand communities" (Schau, Muñiz \& Arnould 2009), "subcultures of consumption" (Arsel \& Thompson 2011) and "consumer tribes" (Cova \& Cova 2002). In contrast to 'mainstream' markets which are alienating to consumers (Maffesoli 1996), more meaningful cultural spaces can be experienced converging in "neotribal" communities, with common ideas and interests. In line with this thinking, we might expect responsible tourists, as a seemingly discernible subculture of the tourism market, to converge around shared cultural ideals.

To date, this more nuanced view of responsibility in consumer contexts has received scant attention in tourism research and practice. However, tourism represents an important and unique social context for the study of responsible consumers. In tourism, the idea of firms seeking to benefit from socially responsible market offerings gains an added layer of complexity compared to say, the marketing of a responsible coffee brand, in that the tourism consumer actively participates in, and materially affects, through their behaviors, some of the potential for responsibility in the tourism experience. Tourists thus both consume and constitute responsible tourism.

This poses a number of theoretical and empirical challenges. As Miller, Rathouse, Scarles, 
Holmes \& Tribe (2010) have argued, many of the studies of responsible consumers rely on behavioral models that are too general and simplistic to be able to explain the complex processes and situational variables that influence responsible behavior. Instead, they propose, closer attention should be paid to the language that tourists use and how these frame tourist decisions in terms of specific acts and roles (see Dann 1996). Little attention has yet focused on consumers' own experiences of responsible tourism, its benefits and drawbacks, and the various questions, tensions, and contradictions it may raise.

In this study, we seek to address this gap by providing a new bottom-up perspective on responsible tourism that starts with how tourists make sense of responsibility. The study adopts a socially constructed perspective on reality (Berger \& Luckmann 1966), viewing the consumer's experience of responsible tourism as an important element in the institutionalized, cultural meaning attached to the phenomenon. An important tenet of this perspective is that the meaning of responsibility is discursively constructed (Fletcher 2009), mediated by tourism texts, images and narratives. Responsible tourism provides a cultural viewpoint through which tourists interpret themselves and others as subjects of meaningful social practices. Central to this is the construction (and institutionalization) of a specific tourist identity, readily identifiable as responsible to consumers, and orientated towards ostensibly 'responsible' social practices and relations with others.

Whilst there has been some work that has examined how responsible identities are constructed for tourists by marketers (Caruana \& Crane 2008), few studies have explored tourists' own constructions of responsible tourism, how they attempt to define and justify themselves as responsible and whether at all (and if so, by what degree), they might align with the construction of responsible tourism as constructed by the industry. To address this omission we take tourists' accounts of their experience of responsible holidays to be neither culturally or morally neutral and seek to explore the very active ways in which ostensibly 'responsible' tourists construct their positionality in relation to their tourism experience.

\section{STUDY METHODS}

Our constructionist, interpretive perspective informed a qualitative research framework to collect and analyze the empirical data. For this study we sought to select practicing responsible tourists by recruiting and screening a "purposive" (Silverman, 2006) sample of informants who were deemed theoretically relevant to the study's core research questions. Therefore we intentionally selected tourists who all had recently booked holidays with Responsibletravel.com, assuring us that they possessed first-hand experience of, and could thus talk meaningfully about, the phenomenon under investigation (Silverman, 2006). This process enhanced the theoretical relevance of the sample, not only because

Responsibletravel.com is the UK market leader in "ethically screened" holidays, but because the range of holiday categories offered (e.g. family, luxury, adventure, community) all reflected the broad economic, social and environmental conceptions depicted in the literature, namely "travel experiences that also benefit communities and conservation." This purposive sampling led to the identification of and subsequent in-depth interviews with 16 such consumers, characterized in table 1 below. Although the key premise of our sample selection was tourists' direct product experience it is useful to note the absence of any dominant demographic characteristic of the sample: the age, gender, life-stage and occupations varied considerably. Although our study makes no claims to cultural or national influences on responsible tourism, all respondents were from the UK. 
Participants in the study were assured of their anonymity via the use of pseudonyms. Our 'depth interviews' (McCracken 1988), lasted between 40 and 70 minutes and were recorded and fully transcribed. The interviews were all led by a key member of the research team, were conducted face-to-face and one-to-one. For reasons we elaborate on further below, the interviews were not 'controlled' for perceived biases (Silverman, 2006). Each interview proceeded from a number of 'grand tour' questions (McCracken 1988), designed to provide background detail and to set the scene for the interviewee (Holstein \& Gubrium 1995) before moving into the central topic of responsible tourism. The interviewer used open-ended, nonleading questions such as 'when you think of a responsible holiday, what comes to mind?', and 'can you please tell me what you meant by that?' This type of questioning has been described by Arsel \& Thompson (2011) as 'phenomenological interviewing', enabling the respondent to construct narrative accounts of their experiences of responsible tourism from a wider nexus of discourses (Fletcher 2009). Our interpretivist take on 'phenomenological interviewing' acknowledges that tourist's accounts cannot be readily integrated by singular meta-narratives. Consequently the aim of the interview was not to identify and isolate types of responsible tourist, but to explore in depth the narrative dimensions of the responsible tourism experience.

Our interpretivist approach follows Holstein and Gubrium's (1995) view of the interview as a socially constructed event "involving respondent and interviewer as they articulate ongoing interpretive structures" (1995: 16). This positions the researcher as an expert facilitator who, though not speaking for the respondent, activates their narrative productions through openended, topic-based questioning (Silverman, 2006). Here the respondent may identify with multiple narrative positions (Arsel \& Thompson 2011), even ones that seemingly contradict each other, allowing the researcher to explore the linkages between, and context for, the emergence of narrative constructions that are thematically significant. This narrative pluralism is indeed evident across our interviews, with respondents producing varied accounts of responsible tourism, and little evidence of any significant social desirability bias (SDB) (Fischer 1993) as might be expected from a study about "responsibility". Though, again, SDB is a distracting misnomer in our interpretive conceptualization of the interview. All social interactions are effectively performative and representational and respondents are considered as equally 'on stage' in the interview room as they are in other social interactions where the interviewer might be a friend, family member or colleague (Holstein and Gubrium 1995).

The transcripts became the subject of a series of iterative coding and analysis stages and were undertaken by all four authors, who were either familiar with, or directly involved in, the earlier data collection stage. In order to ensure the theoretical transferability and integrity of the analysis, each researcher undertook an initial round of open coding independently to triangulate the initial findings and identify emergent themes (Silverman 2006). The goal for the adoption of this approach was not to try to develop a greater sense of objectivity and validity of the findings, which has been criticized as a goal of triangulation (Seale 1999). However, this form of investigator triangulation has proven effective across the social sciences in balancing out the subjective interpretations of researchers (Flick 2000). These independent coding schemes were compared collectively to eliminate weak themes, expand, clarify and check the inclusion of categories and themes. Starting out from this open reading of each transcript, the researchers moved progressively through a series of coding stages, which through several consultations, were gradually distilled into higher order codes. 


\section{FINDINGS}

First we show how consumers constructed subjective meanings of responsible tourism. These demonstrate the heterogeneity of responsibility in consumer's formulations. Nine different interpretations of responsible tourism emerged. Respondents could be positioned according to their level of personal involvement in responsible tourism and how involvement was linked to self-identity. Respondents could also be positioned according to how they framed their goal orientation. This multi-dimensionality of responsible tourism is represented in Figure 1. The vertical axis represents the extent to which tourists express involvement in responsible tourism. The horizontal axis represents the extent to which respondent's participation in responsible tourism reflects inner or outer-directed goals.

[Please insert Figure 1 about here]

Whilst the dimensions are continuous, we propose that four possible overarching narratives of responsible tourism can be tentatively outlined. In line with our interpretivist approach, this does not suggest that the narratives we identify are outward reflections of four stable and mutually exclusive tourist types. These are narrative categories, not agent categories, and there should be no assumption that respondent accounts of responsible tourism won't move within or between them. Instead, the findings identify four possible 'positioning narratives' that can be employed in tourist accounts of their responsible holiday experience. These are categorized accordingly: i) Instrumental opportunism - narratives highlighting a low level of involvement and an extrinsic goal direction to responsible tourism; (ii) Mindful minimizing narratives emphasizing a high level of involvement and an extrinsic goal direction; (iii) Educational empathy - narratives emphasizing a low level of involvement and an intrinsic goal direction; (iv) Conscious advocating - narratives highlighting a high level of involvement and an intrinsic goal direction. Reinforcing that these categories do not reflect types of responsible tourists, we have labelled them, for instance, "Mindful Minimizing" and "Conscious Advocating", rather than "Mindful Minimizers" or "Conscious Advocates."

\section{Constructing Responsibility}

Some respondents constructed proto-typical or ideal cultural representations of responsible tourism, articulating their experiences in terms of participation in the local community, sharing wealth with others and 'treading lightly' on the environment. Here are some examples of respondents describing how their holiday involved participation with local people, and immersion into local cultures, ways and communities:

Harry: "They're people that live and breathe this environment day in day out, they know all about it, it's a way of life for them, and so you become a part of that."

Bridget: "So living in the Berber or desert lifestyle is very responsible."

Responsible tourism was also referred to as a mode of preservation, which in the sentences below, incorporate both physical, cultural and economic aspects of a responsible holiday:

Kelly: "Obviously, protecting the environment....reducing carbon footprints."

Phil: "You're actually contributing financially to ensure that there is something left. That we leave a legacy." 
Daphne: "If I go there, I want to learn the traditional things, yes, absolutely. And that does help preserve them, yes."

Had the majority of our respondents narrated their experiences solely along these lines we might have concluded that there was "a common set of value-creating practices," (Schau et al. 2009: 30) and that consumers' narratives represented a process of gradual habituation into the responsible tourist community. However, this was certainly not the case, with such 'typical' views of responsible tourism (e.g. participation/preservation) being supplemented or replaced with a variety of other views.

Some respondents emphasized responsible tourism as a learning experience, a "chance to educate yourself....your children" (Phil), whilst others limited their narratives mainly to questions of 'authenticity', such as: "they're real people" (Stacey). Even less typical still were the sometimes quite vociferous proclamations of responsible tourism as a way of avoiding other types of tourism such as "Vegas-type places" (Phil) and other types of tourist:

Joyce: "The clientele is going to be different, but also, all the idiots-, well, it's not the kind of place that they'd go. That's what we were hoping. You're not going to get the beer-swilling louts and tramps."

Deviating even further from the typical notion of responsible tourism were responses that emphasized merely wanting to avoid commercial places and processes, with no trace of a connection to tourism at all:

Scott: "Do I want to be near a supermarket? No, I don't want to be there. Do I want to be near a shopping mall? No, don't want to be anywhere near that."

\section{Harry: "I really don't like mass marketing."}

In fact there were a total of nine themes of responsible tourism that included, but were not weighted around, typical notions of cultural participation and preservation. As shown in Figure 1, these more typical notions were: (i) learning and education; (ii) participation; (iii) preserving economy, culture, and environment; and (iv) authentic. Less typical were: (v) do the right thing; (vi) nice, quiet and small; (vii) distancing from tourists; (viii) avoiding commercialization; and (ix) honest marketing.

Some of the definitions of responsible tourism seemed not only detached from the core ideals (e.g. nice, quiet and small) or vaguely connected to it (e.g. doing the right thing) but were seemingly at odds with the "other-orientated" mind-set promoted by the industry. That is, a cluster of responses framed responsibility squarely in terms of personal, customer trust in the tour operator:

Joyce: "It did what it said on the tin. There was no fluffing it all up to sell it to you. 'look, buy me, buy me.' It was just genuine.".....

Ken: "Okay, I'd say in terms of if you were providing me with a 'responsible holiday', it would be somewhere where you'd go away, really nice, really secure, not a case of dropping me in the middle of Baghdad" 
Thus where Cova \& Cova describe market segments in terms consumer tribes centered around, "products and services that hold people together as a community of enthusiasts or devotees" (2002: 603), we find responsible tourism to be a largely heterogeneous concept with no strong sense of a shared core ethos or cohesive community. We caution though against generalizing this heterogeneity across all tourism segments, as Caruana, Crane \& Fitchett (2008) have found contrasting homogeneity in the 'independent' segment of the tourism market, and we underline the importance of studying responsibility (as with other tourism segments) in context.

\section{Involvement in Responsible Tourism}

The findings suggested that tourists' accounts could be delineated according to the degree of involvement respondents convey in responsible tourism as a cultural identity. In this section we elaborate on the various ways in which involvement is explicitly and implicitly expressed. This was not simply the case of respondents depicting themselves as being either responsible or not. Instead, respondents tended to carefully position themselves relative to identity categorizations (e.g. eco warrior, volunteer) and practices (e.g. working / homestays / participation) that they associated with responsible tourism as an identity.

In the following passages we see how respondents used explicit narratives to convey the extent of their involvement in responsible tourism:

Angela: "I'm not one of those Greenpeace sort of people."

Stacey: "I'm not one of these eco friendly warriors, who camp out in trees and all that."

Interviewees could convey a fluid sense of ethicality that fitted their own sense of self without committing to a high level of involvement in responsible tourism:

Amanda: "I suppose I am more a basic level than all-out."

Frank: "I've done what I feel I want to do."

Even where there is an explicit understanding that responsible tourism involves sacrifices, obligations and commitments, respondents' narratives ring-fenced their own holiday at the lower end of involvement:

Laura: "See, you could go really far and say you should only travel far if there's a purpose to it, like people travel for business."

Scott: "holidays that can benefit the local community but more from an arm's length distance rather than a hands on approach."...." It's not me, no."

This low-involvement positioning connects with but also deviates from studies of other consumers in specific market segments. In common with studies of luxury (Roper, Caruana, Medway \& Murphy 2011), alternative health (Thompson 2004) and independent tourism (Caruana, Crane and Fitchett 2008), consumer involvement is often contingent upon the construction of an 'ideal' cultural type, to which the group identifies with and gravitates towards; increasing involvement cementing memberships to an 'in-group'. Departing from 
these studies, our respondent's involvement in responsible tourism creates the responsible tourist as an ideal type - a radical and consistent moralist - and in effect withdraws from it.

Low involvement could also be interpreted implicitly where respondents framed responsible tourism in non-typical ways such as honest marketing and/or avoiding commercialism. In these and similar accounts, there are no specific actions, relations or commitments that lead to significant involvement in the idealized view of responsible tourism (participation, preservation etc.). Responsible tourism is simply "something different from the catalogues" [Scott], perhaps as a way of "avoiding commercialism" and/or having a "nice, quiet and small" relaxing break:

Scott: "Sort of, different from here...I mean, in the places where we went, the area that it guided us to, that we ended up going to, there were little villages."

Ken: 'So, 'responsible', yes, I see where you're coming from but for me, just relaxing, really relaxing."

A more moderate level of involvement in responsible tourism was indicated by a few of our respondents when they expressed their reasons for choosing responsible tourism to the extent that it was 'the right thing to do'. When asked why they chose a responsible tourism holiday, for instance, Oliver suggested simply that he wanted "to do things, but I want to do it right," whilst Ken contrasted a responsible holiday of "going away with my girlfriend" with an "irresponsible holiday" of "going away with the boys". Whilst Oliver's passage denotes choosing responsible tourism as an outcome of some general commitment to "right principles", Ken unpacks the 'right thing' further and more explicitly around a) responsible and irresponsible holidays and b) how choosing one upholds personal obligations to his girlfriend. In this sense we have an account that interweaves two identity projects, one more focused on perceived 'good'/'bad' tourism and another on caring/selfish partner. This indicates a moderate degree of involvement in responsible tourism as a holiday that enabled them to be ethically mindful and concerned with (or obligated to) specific others. None of the narratives expressing moderate levels of involvement meaningfully committed to the practices typical of responsible tourism such as participating in local communities (e.g. working with locals).

In contrast to the honest marketing or do-the-right-thing constructions of responsible tourism are those narratives that express a higher level of involvement. This was depicted by some respondents who constructed their experiences of responsible tourism in terms of practices such as sharing wealth, working, volunteering and living with vulnerable others. When asked about how they participated in local communities, respondent's varied both in terms of how far they were prepared to go as well as in terms of how the idea of 'benefits' were distributed between themselves and others:

Nick: "But yes, and working with people, as I say, with volunteering in any way is a good way of sharing our skills and learning what skills other people have and learning how to work together, which sometimes is very difficult because we expect a lot."

High levels of involvement were also communicated by Daphne who recommended getting involved in responsible tourism through practices such as volunteering or working whilst endorsing responsible tourism lodges that sustain local resources: 
Daphne: "Yes, you know, you have to be sensible. But coming to volunteer at a festival or working at an established project, I think, is fantastic, or some of those lodges like Baylin, where they really are... they're using all the solar power as they're trying not to use up local resources. They employ local people, using local products, producing local food, creating employment."

High involvement was also expressed implicitly in extended reflections on complex moral dilemmas that were seemingly invisible or irrelevant to moderate and lower-level involvement positions. Bridget asserted, for instance, a connection between her decision to stay with local people and her life-long passion for human rights:

Bridget: "Yes. There are people to talk to and it's just more civilized, isn't it? You're staying in a house rather than a room. People are really important to me, that's why I do what I do. It's my passion for human rights which is my driving force and the more I can learn about other people's lifestyles, the better really."

It was interesting that these accounts of higher involvement did not problematize the commercial context of their relationship with either nature or culture, i.e. as tourists. Previous studies of highly committed ecological consumers, for instance, have observed that respondents' involvement is commonly tied to a fervent claim that "I am not a consumer" (Dobscha \& Ozanne 2001), where consumption is presented as a roadblock to responsibility. Neither the low, moderate or, more crucially, high involvement accounts evidenced this kind of narrative de-coupling of tourism (consumer) from responsibility.

In sum, there was no dominant level of, or pathway to, involvement in responsible tourism. Our analysis revealed that respondents positioned themselves to different degrees in relation to an (often idiosyncratic) idea of responsibility. This positioning proceeded without respondents 'gravitating to a common norm'. In contrast to other studies of where involvement is expressed in distinguishing the 'in-group' from "the 'normal' people who are 'out"' (Cova \& Cova 2002: 72), there was a) no discernible 'in-group' nor a 'normal' 'out' group and b) no acknowledgement of common practices through which to habituate into the former and depart the latter. Extending this, there was no intra-group comparisons (as found in other consumer studies), for example, between 'higher and lower status' community members (Schau et al. 2009).

However, in line with previous studies that have acknowledged the ways in which respondents position their own activities in contrast to perceived morally inferior stereotypes (McCabe and Stokoe 2004) or as a distinctive type of traveler culture (Urry and Larsen 2012), respondents evoked some of these positioning frames. Yet in our study this was far less of a binary as they sought to map out the contours of their involvement in responsible tourism culture, contrastingly, in diverse, personalized comparisons with idealized subjects such as 'radicalized citizens' (too involved) or 'stereotypical, noisy and irresponsible' tourists (not involved at all). Interestingly, whilst Schau et al. (2009) assert that consumers can only derive value where there is a coherent stock of cultural knowledge augmenting a brand, our respondents successfully narrated their involvement in responsible tourism without submitting to any one particular cultural viewpoint of responsibility.

Goals driving Participation in Responsible Tourism

Our respondents also engaged in what we might refer to as 'morality plays', wherein the 
ethicality of their holidays was dramatized into tensions around nature, culture and economy. Crucially, these narratives revealed how holiday goals were orientated to varying extents either towards outcomes beneficial to the self (inner-directed, extrinsic goals) or to others (outer directed, intrinsic goals). Extrinsic goals are described as goals to make money, control people and to attain social recognition, whereas intrinsic goals include having good social relationships, making significant contributions to the community, helping others, personal growth and so on. The interviews with responsible tourists demonstrated that across a variety of themes, respondents could position their experiences of responsible tourism as oriented to immediate personal interests/benefits, the interests of familial others (spouse/daughter) or, at the furthest extent, benefits to unknown or vulnerable others. The positionality of respondents was mapped onto Figure 1.

\section{Extrinsic Goal Direction of Responsible Tourists}

Perhaps surprisingly, there was a range of examples where respondents articulated selfinterested goals driving their participation in responsible tourism. These tended on the whole to be related to some of the a-typical descriptions of responsible tourism such as honest marketing:

Angela: "They were a lot more in detail than any other website that I've seen. I felt like I actually believed what they were saying. ....It was just lovely, what you're going to expect from it....I, kind of, knew what to expect."

In passages like this, the subject of concern is largely extrinsic goals, with responsibility depicted as a conduit of personal assurance, reliability and quality of the product offer. Here is an extended passage describing responsible tourism as a way of avoiding commercialism and one that directly links to personal benefits in the form of a better quality, good-value holiday:

Joyce: "The hotels, they can't offer top class standard when they're getting $£ 10$ a night that's pays for staffing. You know, being realistic, and you know that Thomas Cook or the big companies like the tour operators, will screw them down on price because, 'Heh, I just won't use you,' whereas when they're out of the equation, it's a totally different ball game. You can give people a decent rate, get excellent service all over, all across the board and pay and still probably be in pocket compared to your tour company. It's better when they're not involved, when you can do it like that."

In addition to responsible tourism as a good value proposition, much was made of the ability of responsible tourism to serve respondent's goals of individuality and self-expression:

Harry: 'I really don't like mass marketing, I like something that's tailor made for individual needs. My needs aren't the same as yours, and aren't the same as everybody else's. I look for things that can be planned accordingly, pertaining to my tastes."

The concern is not so much that mass marketing, or "typical tourists", cause harm to others but that the respondents desire to portray individuality and difference, akin to status motivations (Fodness 1994). However in other examples, respondents expressed a less clear extrinsic goal orientation. These respondents tended to construct extrinsic goals within the context of situational factors, such as familial responsibilities and friendship goals such that 
responsible tourism benefitted children, spouses and/or friends and/or upheld kinship duties to them. In Ken's account, for example, by choosing a holiday that included his girlfriend, rather than "the lads", he was "doing the right thing", i.e. upholding his obligations to her. Other examples of responsible tourism serving familial goals were commonly evidenced in descriptions of learning and education. Effectively, by taking a child or spouse on a responsible holiday they were being good, caring parents by teaching their children about life:

Phil: "Yes, it was part of that. You're contributing towards it. You're contributing towards the education of the children. So that again, they can help look after themselves in the future."

Although Paula for example described responsible tourism largely in terms of honest marketing ("you get what you pay for" she concludes), she put this in the context of responsibilities to care for her disabled daughter who needs accessibility:

Paula: "You're taking a bit of a chance when you're booking it. I have been away with the travel agents last year, and oh gosh, I nearly died when I got there. Well, I can't even tell you what it was like. I actually took her in the travel agents with me, and said to the bloke, 'I don't want anywhere where there are loads of steps, it needs to be on the ground floor.' 'No, fantastic this place.' I could have cried.

[INT] So Responsible gave you-,

Paula: "You get what you pay for."

However, these descriptions tended not to extend beyond immediate relationships and perhaps demonstrate that integration of situational goals and extrinsic dispositional goals (Sirgy 2010) can be useful in differentiating between motives and outcomes and offers potential uses for segmentation.

\section{Intrinsic Goal Direction of Responsible Tourists}

There were also explicit descriptions of more intrinsic, outer-directed goals of responsible tourism that we might more typically expect within the narratives of respondents in this kind of ethical tourism market, where often the explicit outcome of participation is conservation and sharing wealth that is unambiguously promoted for its benefit/protection of others:

Nick: "There will be challenges but on the whole, if you are going to go as a tourist, then the people of that country will probably benefit much more if you go as a responsible tourist. If you don't think you can face those challenges, then go and sit in a hotel and be protected from it."

In some of these passages, the subject of personal experiences is important, yet only so far as it serves a social function in regards the care of others. For example, a key goal of Bridget's participation in responsible tourism was to raise her own awareness of positive and negative impacts that she might have on an economically and socially vulnerable 'community of others': 
Bridget: "I have been on beach holidays in Europe although then I think I did try and interact with the local people but you are less inclined to do that. You just stay in a hotel so you have no understanding of what their lifestyle is and what impact you are having on them whereas, I think, where you are meeting somebody you are having more of an awareness of what your impact is on that community."

However, as with extrinsic orientations, intrinsic goal orientation also exposed some ambiguities. Sometimes respondents seemed to relate outer and inner oriented goals in the same passage. In this sense, our study reveals respondent's responsible tourism goals not as stable, separate or fixed positions (e.g. high outer-directed) but as reflective of complex elliptical movements in goal orientation. This was most evident in respondent's discussions of the economic benefits of responsible tourism to others which were, ostensibly, reflective of outer-directed goals, whereas others were more difficult to categorize as the following extract revealed:

Frank: "The activities that we were doing were with people who were happy to do it. It's not, how to explain it, profit sharing? They're like partners, they weren't staff, they were like partners, everyone, the horse-riding guys and the hair-braiding girls and the poolroom attendant ... it wasn't a flat salary. The more they did, the more they did and it, you know, seemed they were all happy and there was no... usually you'd get this sort of face and the, sort of, maids were walking around with their heads down. ...... It's visible in their demeanour, in the fact that they're obviously enjoying working because, I mean, $90 \%$ of salaries from all these workers goes back to their families."

This narrative depicts sharing wealth as a kind of 'smile bonus' that entices locals to enhance the holiday experience for tourists, perhaps by promoting friendlier service interactions and higher standards. It is not clear whether the orientation is towards personal satisfaction from positive service experience or an orientation to wealth creation in the community demonstrating more ambiguous intrinsic-extrinsic goal orientations. Similarly, whilst participation is typically used as a marker of non-exploitation and concern for others concurrent with intrinsic goals, it can also be used as a marker of authenticity and thus satisfy status goals more congruent with an extrinsic goal orientation.

It may be tempting to interpret such ambiguous statements (including those discussed previously indicating low-involvement) as epitomizing Wheeller's (1993) 'ego-tourist', selfinterested and demonstrating misplaced attitudes and value systems. Indeed, this may offer a fruitful line of analysis. However, our narrative approach limits our focus to the positioning work that responsible tourists produce. The analysis reveals a mixture of goal orientations that are consistent with multidimensional concepts of tourist motivation (Gnoth 1997). Some respondents displayed quite unambiguous intrinsic/extrinsic goals, whereas others were more integrated or mixed. These ambiguities in tourist's constructions of notions of responsibility are played out in storied narratives, which were useful in helping respondents to resolve apparently conflicting orientations in an unproblematic way. Thus rather than appear chaotic or random, respondent's accounts of responsible tourism display coherence between potentially divergent holiday goals.

\section{CONCLUSIONS}

Our analysis reveals that the concept of responsible tourism from the consumer perspective is 
not stable and fixed, but fluid and contingent, suggesting a market with considerable heterogeneity. When asked to define what responsible tourism means to them, consumers emphasized different aspects of their own behavior, their interactions with host populations within tourist destinations, the types or characteristics of destinations or the impacts of their activities or the outcomes for local people. The uniquely 'bottom-up' approach to responsible tourism adopted in this study identified nine main themes of responsible tourism. Some of these frames resonate with the constructions promoted by the industry, but equally clearly consumers fashion their own unique and idiosyncratic narratives that at times draw on these corporate narratives, but at others ignore or contradict them. Therefore, corporate communications around responsible tourism are not hegemonic or all-pervasive (see for example, Caruana \& Crane 2008), but rather at most provide an ideal type against which tourists position their own narratives of identity and meaning.

Tourists drew on depictions of their own experiences to position their engagement in responsible tourism. These depictions helped to frame various roles of respondents, other tourists and often local people or responsible tour operators. These narrative data revealed respondents' knowledge of responsible tourism and the subject positions expressed in relation to it (Holstein \& Gubrium 1995). Tourist's accounts can be shown to construct and frame a socio-moral order of responsible tourism, to place people and places in identity categories (McCabe \& Stokoe 2004), but these were ambiguous and fluid rather than aligned to stable subcultures or responsible tourist tribes (Cova \& Cova 2002). Respondents 'worked' to portray a moral self (Matless 1995), and yet the opacity surrounding responsible tourism perhaps presented respondents with difficulty in making identity claims associated with this particular consumption practice, as opposed to other less ambiguous constructs, such as adventure tourist, backpacker, or luxury tourist. This reveals both an 'ideal type' of responsible tourist and a fuzzy set of possible alternative modes of engagement. Our analysis explicates four distinct narrative categories - mindful minimizing, conscious advocating, educational empathy, and instrumental opportunism.

These four constructions of responsible tourism involved positioning of relative involvement in responsible tourism as a type of tourism activity and tourist's expressed goals from these experiences. There are a number of important implications. Narratives emphasizing a higher level of involvement in responsible tourism (such as mindful minimizing and conscious advocating) are perhaps more likely to reflect consumer's behavioral or attitudinal loyalty towards responsible tour operators, and a higher propensity to repurchase (Boon, Fluker and Wilson 2008). Consumer narratives that emphasized low involvement towards responsible tourism may indicate a set of consumers that might be influenced by marketing communications, informing how campaigns should be framed to avoid stereotypical or insensitive representations (Shepherd 2003). Such consumers might be best engaged by highlighting the additional quality 'spill-overs' to responsible tourism that consumer's value (such as small, local, trustworthy providers) rather than more outer-directed benefits.

Responsible tourists may also move from low towards higher levels of involvement (or vice versa). This suggests that further research is required to understand how attitude and behavior change might be encouraged through different forms of responsible tourism practice and communication (Krider et al. 2010). A goal-driven approach offers a useful framework to interpret values and outcomes of certain behaviors (Sirgy 2010). Extrinsic goals drive demand for different types of services and tour offers than intrinsically motivated experiences. The tourism industry needs to be aware of the varying range of goals of responsible tourists, and design and other responsible practices and initiatives accordingly 
(Manente et al. 2012).

Whilst traditional, top-down approaches to responsible tourism might look at these positions as indicative of relatively fixed and distinct tourist types, the present study observed some contradictory movements between them, such that 'instrumental opportunism' may integrate aspects of responsibility but in ways specific to tourists' personal experiences of their holiday experience. At the same time, 'conscious advocating' may not necessarily exclude those tourists from more self-oriented goals of pleasure, relaxation and adventure. In this sense, our research invites further exploration of the complex processes of tourist positionality, especially at a time where ethical tourist markets are opening up to more mainstream audiences, that will, no doubt, increase the propensity of countervailing cultural discourses in the responsible tourism market.

Further research is required to test attitudes towards responsible tourism as well as to validate the dimensions of involvement and goal directedness and whether these dimensions change tourist's accounts across contexts (e.g. home/away spaces; 'mass'/'bespoke' segments) and times (e.g. pre-/during/post-holiday). The four potential clusters of responsible tourism accounts could be examined in more detail through behavioral segmentation approaches, although caution should be applied in translating these types of narratives onto different types of consumers. Our findings suggest that tourists are more fluid in their positioning around responsible tourism than the contours of market segmentation might typically accommodate. Just as the responsible tourist is largely a myth, so might be the idea that there are stable, concrete sub-segments of responsible tourists out there waiting to be discovered.

\section{REFERENCES}

Ajzen, I. \& Fishbein, M. (1980). Understanding attitudes and predicting social behavior. New-Jersey: Prentice-Hall.

Arsel and Thompson (2011). Demythologizing Consumption Practices: How Consumers Protect Their Field-Dependent Identity Investments from Devaluing Marketplace Myths. Journal of Consumer Research, 37 (5), 791-806.

Berger, P. L. \& Luckmann, T. (1966). The social construction of reality: A treatise in the sociology of knowledge. London: Penguin.

Bhattacharya, C. B. \& Sen, S, (2004). Doing better at doing good: When, why, and how consumers respond to corporate social initiatives. California Management Review, 47 (1), 924.

Boon, P., Fluker, M. \& Wilson, N. (2008). A ten-year study of the effectiveness of an educative programme in ensuring the ecological sustainability of recreational activities in the Brisbane Ranges National Park, South-Eastern Australia. Journal of Sustainable Tourism, 16 (6), 681-697.

Bramwell, B., Lane. B., McCabe, S. Mosedale, J. \& Scarles, C. (2008). Research

Perspectives on Responsible Tourism. Journal of Sustainable Tourism, 16 (3), 253-257. 
Bray, J., Johns, N. \& Kilburn, D. (2010). An exploratory study into the factors impeding ethical consumption. Journal of Business Ethics, 98 (4): 597-608.

Caruana, R. \& Crane, A. (2008). Constructing consumer responsibility: exploring the role of corporate communications. Organization Studies, 29, 1495-1519.

Caruana, R. \& Crane, A. (2011). Getting away from it all: Exploring Freedom in Tourism. Annals of Tourism Research, 34 (4): 1495-1515.

Caruana, R., Crane, A. \& Fitchett, J. (2008). Paradoxes of consumer independence: a critical discourse analysis of the independent traveller. Marketing Theory, 8 (3), 253-272.

Co-operative Group (2012). Ethical consumer markets report 2012. Retrieved May $2^{\text {nd }} 2013$ from The Co-operative Website: http://www.cooperative.coop/corporate/Investors/Publications/Ethical-Consumerism-Report/

Cova, B. \& Cova, V. (2002). Tribal marketing: The tribalization of society and its impact on the conduct of marketing. European Journal of Marketing, 36 (5), 595-620.

Dann, G.M.S. (1996). The language of tourism: A sociolinguistic perspective. Wallingford: CABI.

Devinney, T. M., Auger, P. \& Eckhardt, G. (2010). The Myth of the Ethical Consumer. Cambridge: Cambridge University Press.

Dobscha, S. \& Ozanne, J. L. (2001). An ecofeminist analysis of environmentally friendly women using qualitative methodology: The emancipatory potential of an ecological life. Journal of Public Policy and Marketing, 20 (2), 201-214.

Dolnicar, S. \& Leisch, F. (2008). Selective marketing for environmentally sustainable tourism. Tourism Management, 29 (4), 672-680.

Fisher, R. J. (1993). Social desirability bias and the validity of indirect questioning. Journal of Consumer Research, 20 (2), 303-315.

Fletcher, R. (2009). Ecotourism discourse: Challenging the stakeholders theory. Journal of Eco-tourism, 8 (3), 269-285

Flick, U. (2000). Triangulation in qualitative research. In Flick, U., von Kardorrf, E., and Steinke, I. (Eds). A Companion to Qualitative Research (pp. 178-183) London: Sage.

Fodness, D. (1994). Measuring tourist motivation. Annals of Tourism Research. 21, 555-581.

Frey, N. \& George, R. (2010). Responsible tourism management: The missing link between business owners' attitudes and behaviour in the Cape Town tourism industry. Tourism Management, 31 (5), 621-628.

Gabriel, Y. \& Lang, T. (1995). The unmanageable consumer. London: Sage. 
Garriga, E. \& Mele, D. (2004). Corporate social responsibility theories: Mapping the territory. Journal of Business Ethics, 53, 51-71.

Gnoth, J. (1997). Tourism motivation and expectation formation. Annals of Tourism Research, 24, 283-304.

Goodwin, H. \& Francis, J. (2003). Ethical and responsible tourism: Consumer trends in the UK. Journal of Vacation Marketing, 9, 271-284.

Goossens, C. (2000). Tourism information and pleasure motivation. Annals of Tourism Research. 27 (2), 301-321.

Hendarwan, E. (2002). Seeing Green. Global Cosmetic Industry. 170 (5), 16-18.

Holstein, J.A. \& J. F. Gubrium. (1995). The active interview. Thousand Oaks, CA: Sage. Qualitative research methods series number 37.

Holt, D. (2002). Why do brands cause trouble? A dialectical theory of consumer culture and branding. Journal of Consumer Research, 29 (1), 70-91.

Krider, R.E., Arguello, A., Campbell, C. \& Mora, J.D. (2010). Trait and image interaction in ecotourism preference. Annals of Tourism Research, 37 (3), 779-801.

Krippendorf, J. (1987). Ecological approach to tourism marketing. Tourism Management, 8 (2), 174-176.

Maffesoli, M. (1996). The time of the tribes: The decline of individualism in mass society, Sage: London.

Mahrouse, G. (2011). Feel-good tourism: An ethical option for socially-conscious westerners? ACME, 10 (3), 372-391.

Maignon, I. \& Ferrell, O.C. (2004). Corporate social responsibility and marketing: An integrative framework. Journal of the Academy of Marketing Science, 32 (1), pp.3-19.

Manente, M., Minghetti, V. \& Mingotto, E. (2012). Ranking assessment systems for responsible tourism products and corporate social responsibility practices. Anatolia, 23 (1), 75-89.

Matless, D. (1995). The art of right living: Landscape and citizenship, 1918 - 1939 in Pile, S. and Thrift, N. (Eds) Mapping the Subject, Routledge: London.

McCabe, A.S. (2000). Tourism Motivation Process. Annals of Tourism Research, 27 (4), 1049-1052.

McCabe, S. \& Stokoe, E. (2004). Place and identity in tourists' accounts. Annals of Tourism Research, 31(3): 601-622.

McCracken, G. D. (1988). Culture and consumption: New approaches to the symbolic character of consumer goods and activities. Indiana University Press. 
Miller, G., Rathouse, K., Scarles, C., Holmes, K. \& Tribe, J. (2010). Public understanding of sustainable tourism. Annals of Tourism Research, 37 (3), 627-645.

Minton, A. \& Rose, R. (1997). The effects of environmental concern on environmentally friendly consumer behaviour: an exploratory study. Journal of Business Research, 40, 37-48.

Roberts, J. A. (1995). Profiling levels of socially responsible consumer behaviour: A cluster analytic approach and its implications for marketing. Journal of Marketing Theory and Practice, 3 (4), 97-118.

Roper, S. Caruana, R., Medway, D. \& Murphy, P. (2012). Constructing luxury brands: exploring the role of consumer discourse. European Journal of Marketing, 47 (3/4), 375-400.

Schau, H.J., Muñiz Jr, A.M. \& Arnould, E.J. (2009). How brand community practices create value. Journal of Marketing, 73, 30-51.

Seale, C. (1999). Quality and qualitative research. Qualitative Inquiry, 5, 465-487.

Shaw, D., Shiu, E. \& Clarke, I. (2000). The contribution of ethical obligation and self-identity to the theory of planned behaviour: An exploration of ethical consumers. Journal of Marketing Management, 16, 879-894.

Shepherd, R. (2003). Fieldwork without remorse: Travel desires in a tourist world. Consumption, Markets and Culture, 6 (2), 133-144.

Silverman, D. (2006), Interpreting qualitative data: methods for analysing talk, text and interaction, Sage: London.

Sin, H.L. (2010). Who are we responsible to? Locals' tales of volunteer tourism. Geoforum, 41, 983-992.

Sirgy, M. (2010). Toward a quality-of-life theory of leisure travel satisfaction. Journal of Travel Research, 49, 246-260.

SNV (2009). The market for responsible tourism products: SNV Netherlands Development Organization. Retrieved July $11^{\text {th }} 2013$ from the SNV Website: http://www.snvworld.org/en/publications/the-market-for-responsible-tourism-products

Stanford, D. (2008). Exceptional visitors': Dimensions of tourist responsibility in the context of New Zealand. Journal of Sustainable Tourism, 16 (3), 258-275.

Thompson, C. (2004). Marketplace mythology and discourses of power. Journal of Consumer Research, 31 (1), 162-180.

Urry, J. and Larsen, J. (2012) The Tourist Gaze, 3rd edn, London: Sage.

Valor, C. (2008). Can consumers buy responsibly? Analysis and solutions for market failures. Journal of Consumer Policy, 31, 315-326. 
Vermeir, I. \& Verbeke, W. (2006). Sustainable food consumption: exploring the consumer "attitude - behavioural intention" gap. Journal of Agricultural and Environmental Ethics, 19, 169-194

Webster, F.E. (1975). Determining the characteristics of the socially conscious consumer. Journal of Consumer Research, 2, 188-196.

Wheeller, B. (1990). Responsible Tourism. Tourism Management, 11 (3), 262-263.

Wheeller, B. (1993). Sustaining the Ego. Journal of Sustainable Tourism, 1, 121-129.

World Tourism Market Responsible Tourism (2013). About WTM Responsible Tourism. Retrieved July $12^{\text {th }} 2013$ from WTM Website:

http://www.wtmresponsibletourism.com/Content/About-WTM-Responsible-Tourism. 